\title{
Improving outcomes in gastric cancer over 20 years
}

\author{
Anant M. Desai ${ }^{1}$, Manish Pareek ${ }^{2}$, Peter G. Nightingale ${ }^{3}$, and John W.L. Fielding ${ }^{1}$ \\ ${ }^{1}$ Department of Surgery, Queen Elizabeth Hospital, Birmingham B15 2TH, UK \\ ${ }^{2}$ Department of Medicine, City Hospital, Birmingham, UK \\ ${ }^{3}$ Wolfson Computer Laboratory, University of Birmingham, Birmingham, UK
}

\begin{abstract}
Background. Gastric cancer has in the past proven to be a difficult disease to cure. Surgery is the most effective treatment, although the extent of lymphadenectomy undertaken is controversial. This paper examines trends in the detection and treatment of gastric cancer, the move toward targeted surgery, and their impact on survival.

Methods. From 1982 to 2001, 430 patients with gastric cancer were under the care of a single surgeon at the same institution. Copies of the operation records, discharge summaries, and histology reports were retained and subsequently reviewed. Results. Thirty-six patients were excluded from the analysis. Two hundred and five patients $(52 \%)$ had potentially curative surgery for adenocarcinoma and $\mathbf{1 8 9}$ had incurable disease. During the 20-year period, overall 5-year survival increased significantly, from $15 \%$ to $41 \%(P<0.01)$. The number of curative procedures also increased significantly, from $33 \%$ to $73 \%(P 1<0.001)$ as disease was detected earlier, and 5-year survival in these patients increased from $26 \%$ to $46 \%$. Eightyseven D1, $92 \mathrm{D2}$, and 26 targeted procedures were performed, with 30 -day mortalities of $5 \%, 9 \%$, and $5 \%$, respectively. The 5-year survival was $47 \%$ for D1, $42 \%$ for D2, and $66 \%$ for targeted surgery.

Conclusion. This paper demonstrates an improvement in the stage at which disease was detected and improvement in longterm survival for patients with gastric cancer. The development of targeted surgery has shown promising early results.
\end{abstract}

Key words Gastric cancer · Survival · Surgery · Lymphadenectomy $\cdot$ Sentinel lymph node

\section{Introduction}

Twenty-three years ago, Cancer Registry data from the West Midlands demonstrated that the overall 5-year survival for gastric cancer was $4.5 \%$ [1]. Five-year sur-

Offprint requests to: J.W.L. Fielding

Received: March 22, 2004 / Accepted: June 14, 2004 vival following potentially curative total gastrectomy was only $9.5 \%$, and the vast majority of patients did not have an attempt at resection. Over a 20-year period, an evolutionary approach to the introduction of early diagnosis strategies, surveillance programs, different types of surgery, and adjuvant treatments has been adopted. This paper examines the influence of these changes and their relative impact on the long-term survival of patients. Various published trials of chemotherapy and radiotherapy have demonstrated no consistent benefit in terms of survival when compared to placebo, and further trials are underway [2-8].

Surgery is therefore the mainstay of treatment, although optimal surgical management is controversial, particularly with regard to lymphadenectomy. Following the publication of the results of radical surgery in Japan $[9,10]$, D2 lymphadenectomy was widely adopted in the United Kingdom and Europe, until two large randomized controlled trials were initiated to investigate the safety and efficacy of the extended versus the limited lymphadenectomy [11-14]. Both trials, one in the United Kingdom and the other in Holland, showed no benefit for D2 gastrectomy and showed that the D2 gastrectomy was associated with a higher postoperative mortality, increased postoperative morbidity, and increased length of hospital stay. These trials have led to attempts to limit the radicality of surgery without compromising the efficacy and, hence, the rate of locoregional recurrence.

The concept of the sentinel node was first introduced to cancer surgery in 1977 [15]. This concept was then modified and applied to early-stage malignant melanoma by Morton et al. [16], who reported that the first lymph node to which drainage flowed could be identified by injecting dye into the tumor. Subsequently these principles have been applied to gastric cancer, but due to the relatively complex lymphatic drainage of the stomach, there is often a failure to identify a single node $[17,18]$. We suggest groups of lymph nodes at the 
junction of the N1 and N2 tiers, which can be used as a guide to the type of surgery to be performed.

In 1984, an early diagnosis and surveillance program was started at the Queen Elizabeth hospital. Any patient presenting with any degree of dyspepsia and over the age of 40 was referred to special dyspepsia clinics and seen within 2 weeks. The majority then had an upper gastrointestinal endoscopy performed within a further 2 weeks. Patients with premalignant changes were offered yearly endoscopic surveillance of their lesions, while those with cancers were treated appropriately. The impact of this surveillance program and the type of surgery undertaken on the survival of patients is explored in this paper.

\section{Patients and methods}

Over a 20-year period, from 1982 to 2001,430 patients with gastric cancer were under the care of a single surgeon at the same institution. A copy of the operation record, the discharge summary, and the histological report was retained for each patient, as appropriate. These resources form the basis of this retrospective analysis.

Histological staging was reported using the Union Internationale contre le Cancer (UICC), third edition, in patients presenting before 1987 [19], the fourth edition in those presenting between 1987 and 1997 [20], and then the fifth edition [21] until the end of the series. We have subsequently analyzed data according to our own Birmingham classification to help standardization [22] (see Table 1). The later UICC classification relied on the number of lymph nodes resected and found to be involved and could not be applied to data from the

Table 1. Birmingham staging for gastric adenocarcinoma

\begin{tabular}{|c|c|c|}
\hline Stage & Clinical & Pathological \\
\hline I & $\begin{array}{l}\text { Radical resection } \\
\text { (T1N0M0) }\end{array}$ & $\begin{array}{l}\text { Muscularis propria - } \\
\text { Serosa - } \\
\text { Node - } \\
(\mathrm{T} 1 \mathrm{~N} 0 \mathrm{M} 0)\end{array}$ \\
\hline II & $\begin{array}{l}\text { Radical resection } \\
\text { (T2-4N0M0) }\end{array}$ & $\begin{array}{l}\text { Muscularis propria }+ \\
\text { Serosa } \pm \\
\text { Node }- \\
(\mathrm{T} 2-4 \mathrm{~N} 0 \mathrm{M} 0)\end{array}$ \\
\hline III & $\begin{array}{l}\text { Radical resection } \\
\text { (TX-4N1-3M0) }\end{array}$ & $\begin{array}{l}\text { Muscularis propria } \pm \\
\text { Serosa } \pm \\
\text { Node }+ \\
(\mathrm{TX}-4 \mathrm{~N} 1-3 \mathrm{M} 0)\end{array}$ \\
\hline IVA & $\begin{array}{l}\text { Palliative resection } \\
(\mathrm{TX}-4 \mathrm{NX}-3 \mathrm{M} 0-1)\end{array}$ & $\begin{array}{l}\text { Residual disease } \\
\text { (TX-4N0-3M0-1) }\end{array}$ \\
\hline IVB & $\begin{array}{l}\text { No resection } \\
(\mathrm{TX}-4 \mathrm{NX}-3 \mathrm{M} 0-1)\end{array}$ & T4N0-3M0-1 \\
\hline
\end{tabular}

beginning of the series because this information was frequently unavailable. It has also been shown that insufficient lymph nodes are identified within the specimen (i.e., fewer than 15 lymph nodes) for reliable assessment in between $30 \%$ and $70 \%$ of cases.

All patients with malignancy of the stomach had data stored, but only those with histologically proven adenocarcinoma of the stomach were entered for further statistical analysis.

Surgery was defined as curative when resection margins were clear, there was no evidence of macroscopic disease at the end of surgery, and the intention at the outset of the procedure was to cure. All patients had intraoperative frozen section analysis of paraaortic (N3) lymph nodes, and if involved, attempted curative surgery was abandoned. D1 surgery involved removal of lymph nodes in the perigastric region en-bloc with the resection specimen. In addition to this, lymph nodes at the origin of the left gastric artery were also taken. These are defined as N2 nodes by the Japanese classification [23], but it has become practice in the United Kingdom to excise these nodes during D1 lymphadenectomy. D2 surgery required the removal of lymph nodes along the celiac axis, the hepatoduodenal and retroduodenal nodes, and the splenic and retropancreatic nodes. In the latter half of the study, the concept of targeted surgery was developed. Junctional lymph nodes were defined and sampled intraoperatively (see Table 2). If involved, a formal D2 gastrectomy was performed (targeted D2) and if not, only perigastric and left gastric nodes were excised. These operations were defined as targeted D1.

From 1986 to 1993, eligible patients were entered into the Medical Research Council (MRC) trial $[13,14]$ and randomized to D1 or D2 surgery. Prior to the trial, patients generally underwent routine D2 gastrectomy and, following the trial, the concept of targeted surgery began to develop.

Operations were tailored to each patient and evolved over the time period under study to reflect wider, evidence-based, changes in surgical practice. In those

Table 2. Junctional nodes for tumors of the upper, middle, and lower thirds of stomach

\begin{tabular}{llc}
\hline Site of tumor & Junctional nodes & $\begin{array}{c}\text { Station number } \\
\text { by JRSGC }\end{array}$ \\
\hline Upper third & Left gastric & 7 \\
& Short gastric & 4 sa or $4 \mathrm{sb}$ \\
Middle third & Left gastric & 7 \\
& Suprapyloric & 5 \\
Lower third & Left gastric & 7 \\
& Suprapyloric & 5 \\
\hline
\end{tabular}

JRSGC, Japanese Research Society for Gastric Cancer 
Table 3. Trends in gastric cancer management by 5 -year period

\begin{tabular}{lrrrrr}
\hline & $1982-1986$ & $1987-1991$ & $1992-1996$ & $1997-2001$ & Total \\
\hline D1 & 8 & 21 & 26 & 32 & 87 \\
D2 & 12 & 23 & 44 & 13 & 92 \\
Targeted surgery & 0 & 0 & 3 & 23 & 26 \\
Palliative surgery & 30 & 27 & 12 & 4 & 73 \\
Open/close & 3 & 15 & 9 & 3 & 30 \\
No operation & 7 & 13 & 48 & 18 & 86 \\
Other & 5 & 5 & 12 & 14 & 36 \\
Total & 65 & 104 & 154 & 107 & 430 \\
\hline
\end{tabular}

patients in whom curative surgery was not possible, patients had no operation at all, had a laparotomy at which the tumor proved unresectable, had a palliative procedure, or had an attempted curative operation but margins were subsequently found to be involved.

\section{Statistical analysis}

The 20-year period covered by this study was divided into four consecutive 5-year periods. Trends in proportions over these four periods were analyzed with the test for linear by linear association. Comparisons of two proportions were made with Fisher's exact test. The method of Kaplan and Meier was used to estimate survival. Survival distributions were compared with the log rank test. All statistical analysis was performed using SPSS 10.0 for Windows (SPSS, Chicago, IL, USA).

\section{Results}

During the study period, 430 patients presented with malignancy of the stomach. Among these there were 15 patients with lymphoma and 3 patients with sarcoma and these patients were excluded from further analysis. A further 10 patients had completion gastrectomy for recurrent or residual disease and 8 had esophagogastrectomy for cardia tumors, and they were also excluded.

One hundred and eighty-nine patients $(48 \%)$ were incurable at the time of presentation. Eighty-six patients $(22 \%)$ had no procedure performed because disease was too advanced, or because the patient was unfit for anesthetic or refused surgery. Thirty patients $(8 \%)$ had a laparotomy at which it was discovered that, despite preoperative staging techniques, the tumor was unresectable and no further procedure could performed. Seventy-three $(19 \%)$ patients had procedures which were aimed, at the outset, to palliate the symptoms without any attempt to cure the patient.

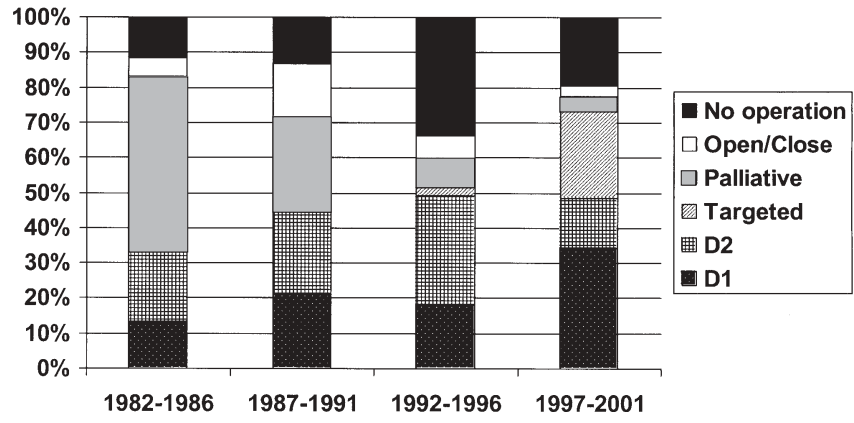

Fig. 1. Trends in gastric cancer management

Two hundred and five patients (52\%) had surgery for adenocarcinoma which was deemed to be curative. The average age of the patients was 68.3 years, and there was a male preponderance of 2 to 1 . One hundred and six patients had total, while 99 had distal gastrectomy, and there were 87 D1 and 92 D2 procedures performed. There were also 26 targeted procedures performed in total, 22 in patients having negative junctional nodes who therefore had targeted D1 gastrectomy, and 4 who required D2 due to involvement of these nodes. Fiftythree out of the 205 (26\%) patients of this group had early gastric cancer which was confined to the mucosa or submucosa regardless of nodal stage. Forty-six patients had Birmingham stage-one disease, in which only mucosa or submucosa, but no lymph nodes, were involved. Fifty-six patients had stage two, and 126 had stage three.

The trends in the type of surgery performed are shown in Table 3 and Fig. 1. Table 3 shows that the number of patients who underwent potentially curative surgery increased significantly $(P<0.001)$, from 20 $(33 \%)$ in the first 5 years to $68(73 \%)$ in the last 5 -year period, and this is reflected in the significantly greater proportion $(P<0.001)$ of patients who had stage I to III disease at presentation (see Fig. 2). While the proportion of curative surgery that was D1 remained fairly constant, the proportion of curative surgery that was D2 decreased from $60 \%$ to $19 \%$, and the targeted 
procedures accounted for $34 \%$ of all curative operations in the last 5-year period. Figure 1 also shows that, in parallel with an increase in curative surgery, there was an overall decrease in the level of palliative surgery, from $50 \%$ of cases to just $4 \%$. There was an increase in the number of patients who underwent no surgical procedure at all, from $12 \%$ to $19 \%$.

Following resection, specimens were examined by the pathologist, and the total number of lymph nodes and the number of involved nodes was identified. In D1 procedures, the mean number of nodes reported was 14 (range, 1 to 48; median, 13) and the mean number of nodes involved was 4 . For D2 procedures, the mean number of nodes resected was 22 (range, 1 to 92; median, 18) and, on average, 4 nodes were involved. In targeted surgery, 3 out of 22 nodes were involved, on average. Importantly, 34 out of 92 patients (37\%) who had D2 surgery had no lymph nodes involved in the disease process.

Overall, for all patients who had a surgical procedure which entailed a laparotomy, the 30-day survival was $91 \%$ and 5 -year survival was $29 \%$. In those patients who

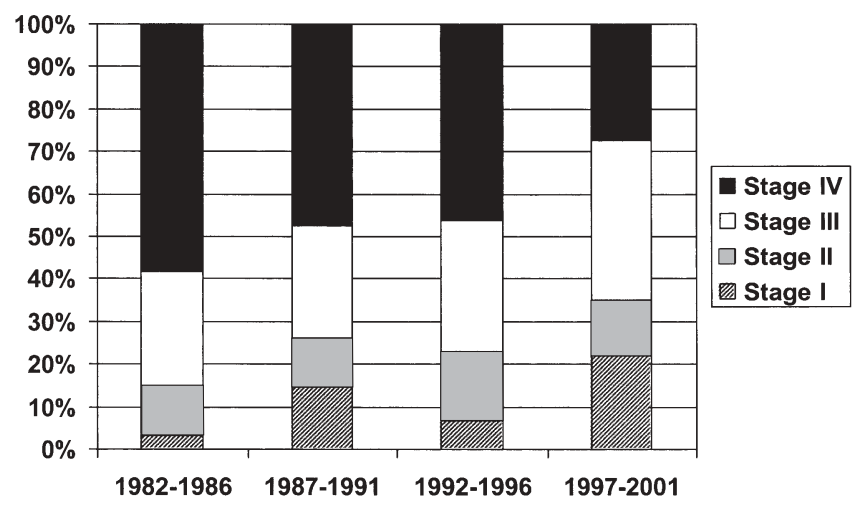

Fig. 2. Changes in stage of disease during study period had potentially curative surgery, 30-day survival was $92 \%$, and at 5 years, $45 \%$ of patients were alive. Table 4 shows the 30-day and 5-year survivals by procedure, with survivals at 5 years of $47 \%$ and $42 \%$ for D1 and D2, respectively, and $66 \%$ for targeted surgery.

Regardless of the type of surgery performed, the single most important predictor of outcome was stage of disease (see Fig. 3). Five-year survivals for stage I, II, and III disease were $78 \%, 42 \%$, and $25 \%$ respectively $(P<0.001)$. There was no significant difference in the survival of patients that had palliative surgery compared to those that had no resection performed (stage $4 \mathrm{~A}$ vs stage 4B). Table 5 shows that overall 5 -year survival has increased, from $15 \%$ in the period 1982-1986, to $41 \%$ in the period 1997 to 2001 . The latter figure is a Kaplan-Meier projected survival, as 5-year follow up is not available for many patients in this group. However, survival had increased significantly $(P<0.01)$, to $33 \%$, in the 1992-1996 period and reflects the promising trend. There is also increased survival in those patients who had curative surgery, but the 30-day survival has not changed.

In those patients who had a potentially curative procedure, the crude rate of complication was $22 \%$. Sixteen patients $(8 \%)$ had radiologically proven anastomotic leaks, 4 patients had hemorrhagic complications requiring further laparotomy, 4 developed intraabdominal collections, 5 patients developed chest infections, and

Table 4. Thirty-day and 5-year survivals by type of procedure

\begin{tabular}{lcc}
\hline & 30-Day survival & 5-Year survival \\
\hline D1 & $95 \%$ & $47 \%$ \\
D2 & $91 \%$ & $42 \%$ \\
Targeted surgery & $95 \%$ & $66 \%$
\end{tabular}

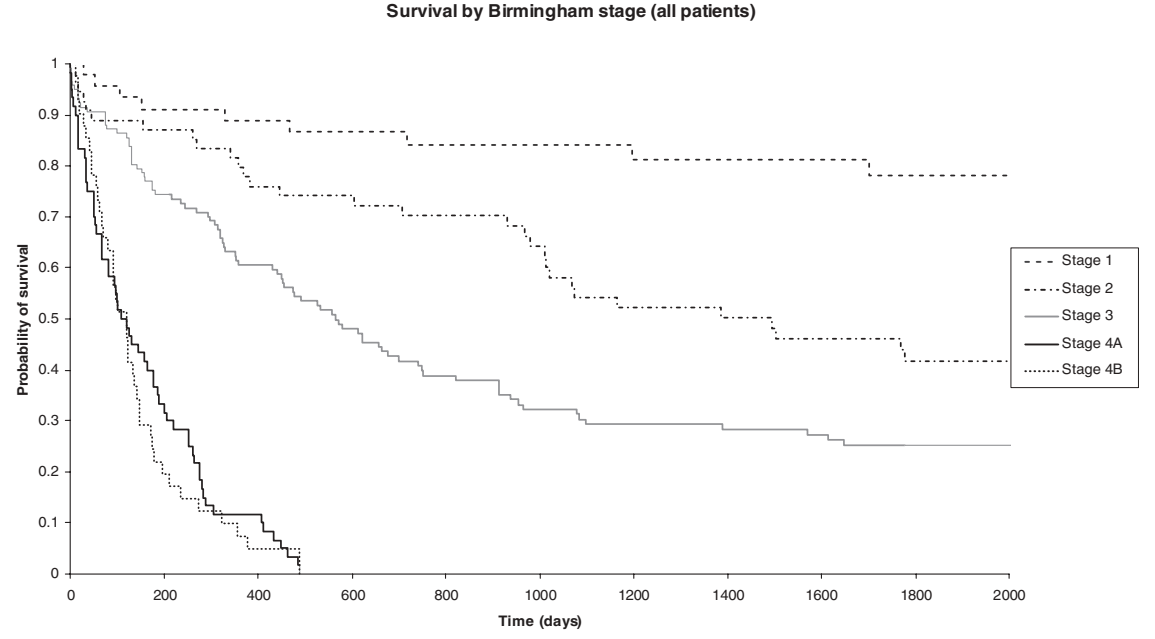

Fig. 3. Kaplan-Meier survival curves 
Table 5. Overall survival and survival for curative surgery by 5-year period

\begin{tabular}{lcccc}
\hline & 1982 to 1986 & 1987 to 1991 & 1992 to 1996 & 1997 to 2001 \\
\hline $\begin{array}{l}\text { Overall 5-year } \\
\text { survival }\end{array}$ & $15 \%$ & $22 \%$ & $33 \%$ & $41 \%$ \\
$\begin{array}{l}\text { 30-Day survival } \\
\text { (curatives) }\end{array}$ & $84 \%$ & $95 \%$ & $91 \%$ & $95 \%$ \\
$\begin{array}{l}\text { 5-Year survival } \\
\text { (curatives) }\end{array}$ & $26 \%$ & $38 \%$ & $47 \%$ & $46 \%$ \\
\hline
\end{tabular}

there were 3 pulmonary emboli. In the patients that had the leaks, mortality was $25 \%$ (4 out of 16 ), and 13 of these events occurred in patients who had a total gastrectomy.

Eighteen patients who had D1 surgery $(21 \%)$ and 31 of the D2 group (34\%) developed complications which were classified as major or minor. In the group that had targeted surgery, the overall complication rate was 4 , in 26 patients $(15 \%)$.

\section{Discussion}

In this series of 430 patients with gastric cancer, we have found that, overall, $52 \%$ have disease that is amenable to potentially curative surgery. This compares favorably with a curative resection rate of $21 \%$ reported in 1989 [1]. Furthermore, the number of patients with curable disease increased over the study period, from $33 \%$ to $73 \%$. The cause of this increase is not clear from these data, but we have previously reported that open-access endoscopy and endoscopic surveillance [24] can detect earlier disease and, hence, increase survival.

In those patients that had curative surgery, operative mortality was $8 \%$, and 5-year survival, $45 \%$. In contrast, in the period 1957 to 1981, operative mortality for total gastrectomy was $29 \%$, and $13 \%$ for partial gastrectomy, and there was no obvious improvement in these figures during that study [1]. In our study, by stage, $78 \%$ of patients with stage I disease survived to 5 years, while $42 \%$ and $25 \%$ of patients with stage II and III disease lived to 5 years. As expected, stage of disease at time of presentation correlates very strongly with survival, and if further progress is to be made in reducing mortality from gastric cancer, efforts to detect the disease earlier need to be prioritized.

In those patients with incurable disease, the number of patients undergoing palliative resection has decreased significantly, and this is in keeping with the growing trend for surgery only in those patients with symptomatic disease where the benefits and goals of a palliative procedure are clearly defined. Since 1997, all patients considered for gastric resection have under- gone staging laparoscopy, and those with positive cytology have been offered palliative treatment only. It has been shown previously that patients with positive cytology on lavage have a statistically significant higher survival rate than those who do not have malignant cells in lavage fluid [25]. In the period 1982 to 1991, 11\% of cases were unresectable on laparotomy, and, while this fell to just $5 \%$ in the second 10 -year period, to 2001, the difference was not significant $(P=0.10)$. However, as mentioned, this practice became routine only in the last 5 years of the study and it is hoped that this trend will continue.

In this study, we found that the rate of complication was higher in patients that had D2 surgery compared to those patients that had D1 or targeted surgery. D2 gastrectomy was accompanied by lower 30-day and 5-year survival rates. Furthermore, $37 \%$ of patients that had D2 surgery had it unnecessarily, as they had node-negative disease and would be expected to do well with less extensive surgery. These findings correlate with those of the MRC trial and with data published in a report from the Association of Upper Gastrointestinal Surgeons, and have led to the development of targeted surgery in which previously described junctional nodes are sampled intraoperatively and analyzed by frozen section. If the nodes are involved, a traditional D2 gastrectomy is performed, and if not, the resection is limited to an extended D1 procedure with the removal of lesser and greater curve lymph nodes, as well as nodes at the origin of the left gastric artery. This has led to promising early results, with $5 \%$ operative mortality and twothirds of patients surviving to 5 years, although this is a carefully selected group with incomplete follow-up.

Significant improvements have been made in stage of detection of gastric cancer and survival from the disease at this center. We feel that this is due to aggressive investigation of symptoms, careful patient selection, and stage-appropriate surgery, although, as it is the work of a single surgeon, it is difficult to make specific recommendations. It is also disappointing that it has taken 20 years to accumulate these results. Hopefully, with the reorganization of upper gastrointestinal services and the consequent increased workload, it will be 
easier to show the effects of new treatments more quickly.

Acknowledgments The authors thank the Hilda Avery Trust, which supported Mr. A.M. Desai, and Mrs. L. May, for her help in the collection of data.

\section{References}

1. Allum WH, Powell DJ, McConkey CC, Fielding JW. Gastric cancer: a 25-year review. Br J Surg 1989;76:535-40.

2. Earle CC, Maroun J, Zuraw L. Neoadjuvant or adjuvant therapy for resectable gastric cancer? A practice guideline. Can J Surg 2002;45:438-46.

3. Fielding JW, Fagg SL, Jones BG, Ellis D, Hockey MS, Minawa A, et al. An interim report of a prospective, randomized, controlled study of adjuvant chemotherapy in operable gastric cancer: British Stomach Cancer Group. World J Surg 1983;7:390-9.

4. Hallissey MT, Dunn JA, Ward LC, Allum WH. The second British Stomach Cancer Group trial of adjuvant radiotherapy or chemotherapy in resectable gastric cancer: 5-year follow-up. Lancet 1994;343:1309-12.

5. Hermans J, Bonenkamp JJ, Boon MC, Bunt AM, Ohyama S, Sasako M, et al. Adjuvant therapy after curative resection for gastric cancer: meta-analysis of randomized trials. J Clin Oncol 1993;11:1441-7.

6. Langman MJ, Dunn JA, Whiting JL, Burton A, Hallissey MT, Fielding JW, et al. Prospective, double-blind, placebo-controlled randomized trial of cimetidine in gastric cancer. British Stomach Cancer Group. Br J Cancer 1999;81:1356-62.

7. Mackay HJ, McInnes A, Paul J, Raby N, Lofts FJ, Mc Donald AC, et al. A phase II study of epirubicin, cisplatin and raltitrexed combination chemotherapy (ECT) in patients with advanced oesophageal and gastric adenocarcinoma. Ann Oncol 2001;12: 1407-10.

8. Allum WH, Hallissey MT, Kelly KA. Adjuvant chemotherapy in operable gastric cancer. Five-year follow-up of first British Stomach Cancer Group trial. Lancet 1989;1:571-4.

9. Hundahl SA, Stemmermann GN, Oishi A. Racial factors cannot explain superior Japanese outcomes in stomach cancer. Arch Surg 1996;131:170-5.

10. Maruyama K, Okabayashi K, Kinoshita T. Progress in gastric cancer surgery in Japan and its limits of radicality. World J Surg 1987:11:418-25.

11. Bonenkamp JJ, Songun I, Hermans J, Sasako M, Welvaart K,
Plukker JT, et al. Randomised comparison of morbidity after D1 and D2 dissection for gastric cancer in 996 Dutch patients. Lancet 1995;345:745-8.

12. Bonenkamp JJ, Hermans J, Sasako M, van de Velde CJ. Extended lymph-node dissection for gastric cancer. Dutch Gastric Cancer Group. N Engl J Med 1999;340:908-14.

13. Cuschieri A, Fayers P, Fielding J, Craven J, Bancewicz J, Joypaul $\mathrm{V}$, et al. Postoperative morbidity and mortality after D1 and D2 resections for gastric cancer: preliminary results of the MRC randomised controlled surgical trial. The Surgical Cooperative Group. Lancet 1996;347:995-9.

14. Cuschieri A, Weeden S, Fielding J, Bancewicz J, Craven J, Joypaul V, et al. Patient survival after D1 and D2 resections for gastric cancer: long-term results of the MRC randomized surgical trial. Surgical Co-operative Group. Br J Cancer 1999;79:1522-30.

15. Cabanas RM. An approach for the treatment of penile carcinoma. Cancer 1977;39:456-66.

16. Morton DL, Wen DR, Wong JH, Economou JS, Cagle LA, Storm FK, et al. Technical details of intraoperative lymphatic mapping for early stage melanoma. Arch Surg 1992;127:392-9.

17. Maruyama K, Sasako M, Kinoshita T, Sano T, Katai H. Can sentinel node biopsy indicate rational extent of lymphadenectomy in gastric cancer surgery? Fundamental and new information on lymph-node dissection. Langenbecks Arch Surg 1999;384:14957.

18. Siewert JR, Kestlmeier R, Busch R, Bottcher K, Rober JD, Muller J, et al. Benefits of D2 lymph node dissection for patients with gastric cancer and $\mathrm{pN} 0$ and $\mathrm{pN} 1$ lymph node metastases. $\mathrm{Br}$ J Surg 1996;83:1144-7.

19. TNM Classification of malignant tumours. 3rd ed. Geneva: UICCInternational Union Against Cancer; 1978.

20. Hermanek P, Sobin LH, editors. UICC. TNM Classification of malignant tumours. 4th ed. Berlin Heidelberg New York Tokyo: Springer; 1987.

21. Sobin LH, Wittekind CH, editors. UICC. TNM Classification of malignant tumours. 5th ed. New York: Wiley; 1997.

22. Fielding JW, Roginski C, Ellis DJ, Jones BG, Powell J, Watermouse JA, et al. Clinicopathological staging of gastric cancer. Br J Surg 1984;71:677-80.

23. Japanese Gastric Cancer Association. Japanese classification of gastric carcinoma-2nd English edition. Gastric Cancer 1998;1: $10-24$.

24. Whiting JL, Sigurdsson A, Rowlands DC, Hallissey MT, Fielding JW. The long-term results of endoscopic surveillance of premalignant gastric lesions. Gut 2002;50:378-81.

25. Bryan RT, Cruickshank NR, Needham SJ, Moffitt DD, Young JA, Hallissey MT, et al. Laparoscopic peritoneal lavage in staging gastric and oesophageal cancer. Eur J Surg Oncol 2001;27:291-7.

\section{Editorial comment}

\section{D2 lymph node dissection in gastric cancer surgery: searching for the individual indication}

J. Rüdiger Siewert

Department of Surgery, Klinikum rechts der Isar, Technische Universität München, München, Germany

The indication for D2 lymph node dissection in gastric cancer surgery remains under intensive controversial debate. Only recently, the long-term results (11 years of follow-up) of the Dutch Gastric Cancer Study, comparing D1 and D2 lymphadenectomy in a randomized controlled setting, have been published [1]. The authors have repeated their analysis and have performed inten- sive subgroup analysis in addition. The data contribute to the ongoing discussion and are helpful for making further recommendations regarding the appropriate extent of lymphadenectomy.

The Dutch Gastric Cancer Study shows no statistically significant survival benefit for the whole populations of patients having undergone D2 lymph node dissection compared with patients having undergone D1 dissection. However, a subgroup of patients appears to have a prognostic benefit from D2 lymphadenectomy: These are the patients in the N2-category (defined as 7-15 infiltrated lymph nodes according to the new recommendations by the International Union against 
Cancer (UICC) [2]. Similarly, other previous investigations, e.g., the German Gastric Cancer Trial [3], have also shown a survival benefit for a subgroup of patients after D2 lymph node dissection. In the German study this survival benefit has been seen in the subgroup with UICC stage II (and possibly stage IIIa as well). In a meticulous meta-analysis of all previously published studies, McCulloch [4] has also been able to identify a subgroup experiencing a survival benefit from D2 dissection. In the meta-analysis these were the patients with serosa-invading tumors (T3 category).

Further evidence substantiating the essential role of extensive lymph node dissection can be derived from several studies highlighting the impact of the lymph node ratio. The ratio between the number of infiltrated lymph nodes and the total number of all lymph nodes removed has been identified as a major prognostic factor, with the subgroup of patients with a lymph node ratio below $20 \%$ experiencing survival benefit. This was shown once again in a recent publication from the Memorial Sloan-Kettering Cancer Center (MSKCC) in New York [5]. The colleagues from MSKCC have highlighted the major impact of a high-quality lymphadenectomy when publishing a nomogram for postoperative prognosis prediction after curative gastric cancer surgery. The lymph node status (number of positive lymph nodes) and the extent of lymphadenectomy (number of resected negative lymph nodes) are major variables in this nomogram. Both a high number of infiltrated nodes and a low number of resected negative nodes have a major and direct negative impact on survival.

All these findings clearly favor an extensive, meticulous lymph node dissection. There is much evidence for a beneficial role of $\mathrm{D} 2$ lymph node dissection in gastric cancer surgery. Unfortunately, only a subgroup of patients is likely to experience this benefit in terms of an improved long-term prognosis. The reason for the beneficial role of D2 lymphadenectomy being limited to subgroups and not seen in the whole population is presumably explained by the relatively small size of these subgroups. In the Dutch Gastric Cancer Trial the subgroup accounted for $12 \%$ of the whole population [1], and in the German Gastric Cancer Study the subgroup accounted for 14\% [3]. The major problem is that it is not possible, as yet, to identify these subgroups of patients preoperatively. Especially, preoperative lymph node staging - by any diagnostic means-has only a low accuracy. These circumstances prevent us from deciding on individual indications for $\mathrm{D} 2$ lymph node dissections preoperatively and planning the operative strategy prior to the operation.

Thus one further idea is to try to identify the subgoup of patients who are likely to benefit from extensive lymphadenectomy intraoperatively. An interesting strategy is presented in the article by the collaborators of J.W.L. Fielding (Birmingham, UK) in this issue of Gastric Cancer [6]. The authors present their 20-year experience of gastric cancer surgery with significant improved results over time and propose a new concept of "targeted surgery." The operation is started with removal of the so-called junctional nodes (lymph node station 7 or 5 , depending on the localization of the primary tumor (Japanese Research Society for the Study of Gastric Cancer [JRSGC]). Depending on the results of histopathologic evaluation of frozen sections, the decision is made for either D1 or D2 dissection. Patients with a positive junctional node receive D2 lymphadenectomy, whereas patients in whom the junctional node is negative receive only D1 dissection. The early results obtained with this strategy are promising. Desai et al. report a markedly improved 5-year survival rate, as well as markedly improved short-term results, reflected in reduced morbidity and mortality rates. The proposed strategy of targeted surgery clearly justifies further investigation.

Perhaps one could achieve further improvements by considering sentinel lymph node mapping as an additional intraoperative diagnostic means. So far, this method has also been extensively studied (with adequate case load) in early cancers. It is not clear, as yet, whether this method is also accurate and thereby applicable in T2 and T3 tumors. But at least in theory, sentinel lymph node mapping might be a concept for further development and improvement of the targeted surgery concept.

Currently, the concept of individualized indication for D2 lymph node dissection by targeted surgery must be regarded as a promising research topic in the field of gastric cancer surgery. Further investigation is warranted, but in clinical practice D2 lymph node dissection should be further recommended as procedure of choice, because the subgroup for which it is clearly beneficial should receive it. The discussion of D2 lymph node dissection is not yet over, as postulated by some [7]. The quality of surgery as a prognostic parameter in gastric cancer surgery, determined by others [8] comprising a basis for modern individualized strategies, is a more favorable trend for the future.

\section{References}

1. Hartgrink HH, van de Velde CJ, Putter H, Bonenkamp JJ, Klein Kranenbarg E, Songun I, et al. Extended lymph node dissection for gastric cancer: who may benefit? Final results of the randomized Dutch Gastric Cancer Group trial. J Clin Oncol 2004;22:2069-77.

2. Sobin LH, Wittekind Ch, editors. UICC. TNM Classification of malignant tumors. 6th ed. New York: Wiley-Liss; 2002.

3. Siewert JR, Böttcher K, Stein HJ, Roder HD. Relevant prognostic factors in gastric cancer. Ten-year results of the German Gastric Cancer Study. Ann Surg 1998;228:449-61. 
4. McCulloch P, Eidi Nita M, Kazi H, Tsuno H, Nagawa H, GamaRodrigues JJ. Gastrectomy with extended lymphadenectomy for the primary treatment of gastric cancer. In: Santoro E, Garofalo A, editors. Gastric cancer in the world 2003. Proceedings of the 5th International Gastric Cancer Congress, 2003, Rome. Rome: Edizioni Scientifiche Romane; 2003. pp. 101-24.

5. Kattan MW, Karpeh MS, Mazumdar M, Brennan MF. Postoperative nomogram for disease-specific survival after an $\mathrm{R}$ resection for gastric carcinoma. J Clin Oncol 2003;21:3647-50.

\section{Comment from a Japanese viewpoint}

Nobuhiko Tanigawa

Department of General and Gastroenterological Surgery,

Osaka Medical College, Osaka, Japan

In this issue of Gastric Cancer, Desai et al. [1] describe their experience of surgical treatment of patients with gastric cancer for the past two decades, showing an improvement in the stage, as well as in long-term survival. They explain that the main reasons for this favorable outcome may include the adoption of open-access endoscopy and refinements in surgical practice. However, their recent improved survival rates after surgery can hardly be explained entirely by the introduction of their "targeted gastric cancer surgery." The improvement may be influenced by the trend toward a decrease in the numbers of stage IV diseases in recent years, as shown in their Fig. 2.

The article by Desai et al. is likely to attract the interest of many readers of the journal. There are, however, some issues that could use further discussion. First, their concept of "targeted gastric cancer surgery" as an indication for D2 lymphadenectomy is based on the results of intraoperative sampling of the No. 7 and/or No. 5 lymph nodes, but those results are not evidence-based. The reported data on the incidence of regional lymph node metastases derived from a huge number of retrieved nodes indicate that (a) the No. 7 node is most frequently involved by cancer metastasis in the second tier of the Japanese classification; and (b)
6. Desai AM, Pareek M, Nightingale PG, Fielding JWL. Improving outcomes in gastric cancer over 20 years. Gastric Cancer 2004;7: 196-203.

7. Petrelli NJ. The debate is over; it's time to move on. J Clin Oncol 2004:22:2041-2.

8. Ajani JA. Operate on my stomach cancer? Oh, no-not you, or not yet! J Clin Oncol 2004;22:1763-4.

that the chance of No. 5 node involvement is least among the first tier [2], indicating that neither of them functions as a pilot node to suggest possible metastasis to the second tier. Second, postoperative mortality rates of $5 \%-9 \%$ and an anastomotic leakage rate of $8 \%$ are almost comparable with the reports from Europe, such as the Dutch trial [3] and an Italian study [4]. Readers who are aware of the data from the Japanese experience of a smaller number of postoperative complications, as well as a mortality rate of less than 1\% [5], are not likely to overlook numbers that may be strongly associated with postoperative survival.

\section{References}

1. Desai AM, Pareek M, Nightingale PG, Fielding JWL. Improving outcomes in gastric cancer over 20 years. Gastric Cancer 2004;7:196-203.

2. Sasako M, Sugimura T, editors. Gastric Cancer. Oxford: Oxford University Press; 1997.

3. Bonenkamp JJ, Hermans J, Sasako M, van de Velde CJ. Extended lymph-node dissection for gastric cancer. Dutch Gastric Cancer Group. N Engl J Med 1999;340:908-14.

4. Degiuli M, Sasako M, Ponti A, Soldati T, Danese F, Calvo F. Morbidity and mortality after D2 gastrectomy for gastric cancer: results of the Italian Gastric Cancer Study Group prospective multicenter surgical study. J Clin Oncol 1998;16:1490-3.

5. Sano T, Sasako M, Yamamoto S, Nashimoto A, Kurita A, Hiratsuka M, et al. Gastric cancer surgery: morbidity and mortality results from a prospective randomized controlled trial comparing D2 and extended para-aortic lymphadenectomy - Japan Clinical Oncology Group study 9501. J Clin Oncol 2004;22:2767-73. 